\section{Florentino Monsalve Murillo}

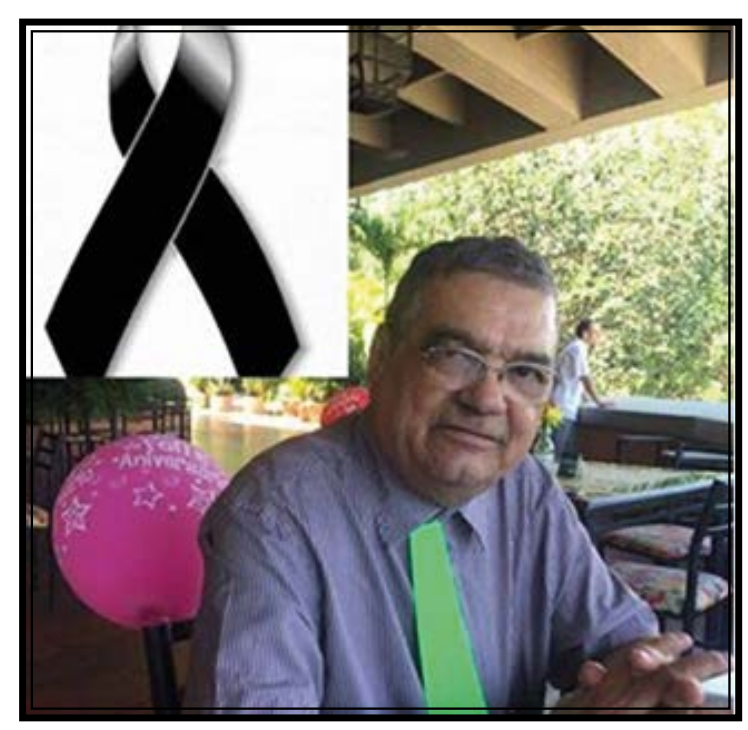

Al profesor Florentino Monsalve Murillodesde muy temprano se le percibieron sus destellos de inteligencia y dotes para las labores académicas. Estudió becado la secundaria y en el seminario, en donde desarrolló su pasión y facilidad de argumentar en grandes auditorios. Trabajó como profesor de inglés para costearse sus estudios de física en la Universidad Industrial de Santander en donde consiguió su título de Magister con la tesis “Determinación espectroscópica de la Temperatura y Densidad Electrónica de un Arco de Corriente Continua". Fue dirigente sindical de las luchas del magisterio santandereano.

Al llegar a la Universidad Surcolombiana, muy pronto ejerció como jefe del programa de licenciatura en Matemáticas y Física y dirigió la elaboración del currículo, con lo que dejó huella en las diversas generaciones de profesores del departamento del Huila, que hoy agradecen la cosmovisión adquirida en esa sistemática, simple y secuencialmente lógica malla curricular.

Su vida dedicada a la docencia, sí que marcan y, más todavía, si se recuerda que desde su inicio interesó a todos los profesores del programa de licenciatura a participar en el seminario de Temas Avanzados, donde él mismo empezó con un curso de matemática avanzada. Era una actividad ad honorem de todos los sábados.

También inició la línea de investigación en energía solar con el trabajo "determinación de las distribuciones espaciales de humedad y temperatura en un horno solar para secado de granos".

Al terminar su Maestría en "Dirección Universitaria en Uniandes" se dedicó a labores administrativas. Como Jefe de Planeación realizó con valentía y perseverancia el primer plan de desarrollo de la Usco aplicando la Planeación Estratégica con objetivos consensuados por la comunidad universitaria, venciendo las hostilidades propias de toda innovación. Con ello demostró su profundo amor a su Alma Máter, la cual convirtió en objeto de estudio científico. Siempre generaba permanente interés en los problemas de la universidad y la forma de resolverlos. Cómo no recordar al ser humano que nunca se permitió que los adversarios en esos debate académico y político se convirtieran en enemigos personales.

Diseñó el software <AUTOEVALPROG>, plataforma que se utilizó durante muchos años para organizar, sistematizar y presentar toda la información referente al proceso de acreditación y publicó sus trabajos "Hacia una universidad comprometida con el desarrollo a escala humana", "Síntesis de los resultados de la autoevaluación de programas con fines de acreditación en la Universidad Surcolombiana", "Del Autoexamen a la Universidad Moderna" y muchos otros trabajos que aportaron a los procesos y teoría de la evaluación de las instituciones educativas. Como Director General De Autoevaluación Institucional publicó “Diagnóstico Estratégico de la Universidad Surcolombiana" "Plan de Desarrollo Universidad Surcolombiana" y promovió el sistema de "Agendas, monitoreo y evaluación académica", SIPAS y los Formatos De Evaluación.

\section{Álvaro Avendaño}

